\title{
The Reproductive Toxicity Associated with Dodonaea viscosa, a Folk Medicinal Plant in Saudi Arabia
}

\author{
Muhammad Farooq Khan ${ }^{D},{ }^{1}$ Ali S. Alqahtani, ${ }^{2}$ Omer M. Almarfadi, ${ }^{2}$ Riaz Ullah $\left(\mathbb{D},{ }^{2}\right.$ \\ Fahd A. Nasr $\mathbb{D}^{2}{ }^{2}$ Omar M. Noman $\mathbb{D}^{2},{ }^{2}$ Nasir A. Siddiqui, ${ }^{2}$ Abdelaaty A. Shahat, ${ }^{2}$ \\ and Syed Rizwan Ahamad ${ }^{3}$ \\ ${ }^{1}$ Department of Zoology, College of Science, King Saud University, P.O Box 2455, Riyadh 11451, Saudi Arabia \\ ${ }^{2}$ Department of Pharmacognosy (Medicinal, Aromatic and Poisonous Plants Research Center), College of Pharmacy, \\ King Saud University, P.O. Box 2457, Riyadh 11451, Saudi Arabia \\ ${ }^{3}$ Central Laboratory, College of Pharmacy, King Saud University, Riyadh 11451, Saudi Arabia
}

Correspondence should be addressed to Muhammad Farooq Khan; fmuhammad@ksu.edu.sa and Riaz Ullah; rullah@ksu.edu.sa Received 19 November 2020; Revised 23 December 2020; Accepted 3 January 2021; Published 15 January 2021

Academic Editor: Armando Zarrelli

Copyright (C) 2021 Muhammad Farooq Khan et al. This is an open access article distributed under the Creative Commons Attribution License, which permits unrestricted use, distribution, and reproduction in any medium, provided the original work is properly cited.

\begin{abstract}
Dodonaea viscosa is a medicinal plant which is being used to treat various diseases in humans. The available safety data suggest that the plant does not produce any side effects, or toxicity, in tested adult experimental animals. However, the influence of $D$. viscosa on fetus or embryonic development is largely not known. This study was conducted in order to find out the reproductive toxicity of $D$. viscosa in experimental animals. Zebrafish embryos were used as the in vivo developmental toxicity animal model. Methanolic crude extract, hexane, chloroform, and butanol fractions were prepared from the leaves of $D$. viscosa. Zebrafish embryos were exposed to serial dilution of crude extract and other fractions. The crude extract and hexane fraction induced higher level of toxicity in zebrafish embryos as compared to chloroform and butanol fractions. The phenol and flavonoid estimation revealed that crude leaves extract and hexane fractions had lower content of phenol and flavonoid. Two major compounds, phytol and methyl ester, of hexadecanoic acid were identified by gas chromatography and mass spectrophotometry (GC-MS) analysis. More detailed studies are needed to check the toxicity of D. viscosa in pregnant experimental animals; however, the results from this study have shown that D. viscosa possesses reproductive toxicity and its use and doses must be carefully monitored in pregnant patients.
\end{abstract}

\section{Introduction}

In recent years, there has been a renewed interest into the biological activity of traditional plant medicines, and the role of natural products in drug discovery [1-3]. Reasons for this include the great need for new molecular models, as this leads to potential new drugs, and for authenticating traditional applications for use in current therapy [4]. Dodonaea viscosa is an evergreen shrub belonging to the Sapindaceae family that consists of about 150 genera and 200 species [5]. Initially, it was a native of Australia and later widespread throughout the tropical regions [6]. In Saudi Arabia, $D$. viscosa is widely found in the southern province,
Hijaz region, and eastern region [7]. It has been accounted as one of the famous traditional remedies for wide verities of ailments like rheumatism, fractures, diarrheas, gout, hepatic or splenic pain, smooth muscles disorders (uterine pain), hemorrhoids, snake bites, and sore throat [8]. The literature review has shown that ethanol extract of $D$. viscosa flower exhibits cytotoxic activity against breast cancer in an in vitro study [9]. Moreover, the anticancer activity of the ethanol extract through induction of apoptosis in human breast cancer cell line has been reported [10]. In addition, dodonaeasides A and B, triterpenoid saponins, were isolated from ethyl acetate extract of $D$. viscosa roots and showed antiproliferative property against human ovarian cancer cell 
line [11]. Besides, the literature review revealed other biological activities of $D$. viscosa such as antimicrobial, antioxidant [12], anti-inflammatory [13], analgesic, antipyretic [14], antifungal [15], gastroprotective [16], antimalarial [17], and antispasmodic activities [18]. Furthermore, phytochemical screening has shown that $D$. viscosa contains flavonoids, alkaloids, terpenoids, saponins, sugars, and tannins [19]. Due to the diverse biological properties $D$. viscosa possesses, various remedies prepared from it are routinely used by humans to cure many ailments. Some studies have reported that $D$. viscosa has not produced severe toxicity in experimental animals; however, the toxicity of $D$. viscosa on developing fetus in human, or in other experimental animals, is largely not known. Therefore, this study was designed to investigate the developmental toxicity of various extracts prepared from the leaves of D. viscosa in zebrafish embryos.

\section{Materials and Methods}

2.1. Plant Collection. Fresh leaves of D. viscosa (Sapindaceae) were collected from the Herbal Garden, College of Pharmacy, King Saud University, Riyadh, Saudi Arabia, and botanically identified by Dr. Mohammed Yusuf, Field Taxonomist, Department of Pharmacognosy, College of Pharmacy, King Saud University. A voucher specimen (voucher \#15787) was deposited at the herbarium of Pharmacognosy Department, College of pharmacy, KSU, Riyadh, KSA.

2.2. Extraction. 428 grams of air-dried leaves was ground to a coarse powder using an electrical grinding mill and extracted by cold maceration in $1200 \mathrm{~mL} 80 \%$ methanol (Sigma-Aldrich, MO, USA), at room temperature and allowed to stand overnight for 3-4 days with occasional shaking to produce crud extract; this process was repeated 3 successive times. Then, the crude extract was filtered using Whatman filter paper No. 1 (Wagtech International Ltd., England) and concentrated using a rotary vacuum evaporator (Buchi Rotavapor) under reduced pressure at $45 \mathrm{rpm}$ and controlled temperature $\left(40^{\circ} \mathrm{C}\right)$. After drying, a total of dry crud extracts, 133 grams, was kept in the refrigerator until use.

2.3. Solvent Fractionation. 128 grams of the crude extract was subjected to fractionation fractions using increasing polarity organic solvents purchased from Sigma-Aldrich, MO, USA (i.e., $n$-hexane, chloroform, ethyl acetate, and $n$ butanol) successively. It was transferred to a separatory funnel and suspended in $475 \mathrm{~mL}$ of distilled water and partitioned with $3 \times 500 \mathrm{~mL}$ of each solvent. The filtrate was concentrated using a rotary vacuum evaporator under reduced pressure at $45 \mathrm{rpm}$ and $40^{\circ} \mathrm{C}$. The yield of the dried fractions was $0.86 \%, 27.56 \%$, and $23.95 \%$ for the $n$-hexane, chloroform, and $n$-butanol fractions, respectively. Then, the dried fractions were transferred into separate vials and stored at $-20^{\circ} \mathrm{C}$ until use.

\section{Phytochemical Analysis}

3.1. GC-MS Analysis and Compound Identification. The chemical constituents of D. viscosa hexane fraction (DVHF) were determined using gas chromatography and a mass spectrometer (Turbomass, PerkinElmer, Inc., Waltham, MA, USA). The temperature of program 4 was set to $40^{\circ} \mathrm{C}$, followed by a $2 \mathrm{~min}$ hold, and then raised to $200^{\circ} \mathrm{C}$ at a rate of $5^{\circ} \mathrm{C} \mathrm{min}{ }^{-1}$, which was also then put on hold for $2 \mathrm{~min}$. From $200^{\circ} \mathrm{C}$, the temperature was raised by $5^{\circ} \mathrm{C} \mathrm{min}^{-1}$ to $300^{\circ} \mathrm{C}$ and held for another $2 \mathrm{~min}$. The mass spectra of DVHF compounds were also compared with those of similar compounds in the Adams Library [20] and the Wiley GC/MS Library [21].

\subsection{Estimation of Total Phenol and Flavonoid Contents.} Total phenolic content of D. viscosa extract and fractions was determined by the standard Folin-Ciocâlteu spectrophotometric method [22, 23]. Briefly, $0.5 \mathrm{~mL}$ of each extract was added to $0.1 \mathrm{~mL}$ of Folin-Ciocâlteu reagent $(0.5 \mathrm{~N})$ and the contents of the flask were mixed thoroughly. Later, $2.5 \mathrm{~mL}$ of sodium carbonate $\left(\mathrm{Na}_{2} \mathrm{CO}_{3}\right)$ was added, mixed, and incubated for $0.5 \mathrm{~h}$. The optical density was measured at $760 \mathrm{~nm}$ utilizing UV-visible spectrophotometer. The total phenolic contents were expressed as mg gallic acid equivalents (GAE)/ $\mathrm{g}$ of the extract. For total flavonoids content, standard aluminium chloride spectrophotometric method according to [24] was used. In brief, $1 \mathrm{~mL}$ of each extract at a concentration of $1 \mathrm{mg} / \mathrm{mL}$ was taken. Then, $1 \mathrm{~mL}$ of $\mathrm{AlCl}_{3}(10 \%)$ was added sequentially. The test solution was vigorously shaken. Absorbance was recorded at $415 \mathrm{~nm}$ after 30 minutes of incubation.

3.3. Animal Test. Zebrafish embryos less than 5 days after fertilization were used in this study and hence exempted from taking approval from institutional ethical committee for the care and use of laboratory animals as stated in [25]. Maintenance and breeding procedures were performed by following the guidelines mentioned in zebrafish book [26]. Embryos were obtained after pairwise mating of adult fish in one-liter sterile breeding tanks by putting two females and one male. Embryos were collected and washed using embryo medium fertilized and dead embryos were separated according to the descriptions of Kimmel et al. [27].

3.4. Embryo Short-Term Toxicity Test. Fertilized embryos were transferred into 6-well plates (30 embryos/well) containing a series of diluted extracts ranging from $0.15 \mu \mathrm{g} / \mathrm{mL}$ to $300 \mu \mathrm{g} / \mathrm{mL}$ in total volume of $2 \mathrm{~mL}$ and incubated overnight in an air incubator at $29^{\circ} \mathrm{C}$. Embryo development was monitored first after overnight and then after every $24 \mathrm{~h}$ interval for $96 \mathrm{~h}$. Four morphological characteristics were evaluated including coagulation of eggs, tail detachment, presence of heart beat, and hatching rates using Carl-Zeiss Inverted Microscope (observer D1) equipped with differential interference contrast (DIC) filter and camera and 
software for image optimization. Experiments were conducted in triplicate.

3.5. Calculation of LC50. Median inhibitory concentration $\left(\mathrm{IC}_{50}\right)$ and median lethal concentration $\left(\mathrm{LC}_{50}\right)$ were statistically analyzed by using the Probit analysis using Excel spread sheet as stated in [28].

3.6. Acridine Orange Staining in Whole Mount. Apoptosis was analyzed in hexane extract of $D$. viscosa treated wholemount embryos with an exposure to the sub-lethal concentration of $0.5 \mu \mathrm{g} / \mathrm{mL}$ at $24 \mathrm{hpf}$ (hours post fertilization). Control and treated embryos were rinsed several times with distilled water and then exposed to a solution of acridine orange (Carlo Erba) at a concentration of $100 \mu \mathrm{g} / \mathrm{mL}$ for $1 \mathrm{~h}$, after which several rinses were performed to remove the excess dye. The embryos were then mounted in a drop slide with glycerol and PBS. The images were acquired with Olympus SZ10 florescent microscope using FITC channel.

\section{Results and Discussion}

4.1. DVHF Chemical Composition. Figure 1 shows the retention times and area percentages of DVHF. In Table 1, the identified compounds are represented in order of their elution on the HP Innowax column. A total of 9 compounds, representing $98.99 \%$ of the total extract, could be identified. 3,7,11,15-Tetramethyl-2-hexadecen-1-ol (52.7\%) (Figure 2) was the primary constituent, and methyl ester of hexadecanoic acid (26.3\%) (Figure 2) was a moderate constituent. The other compounds are present in fairly good amounts.

\subsection{Estimation of Total Phenol and Flavonoid Contents.} The total phenolic content of the D. viscosa extract and fractions was measured with the Folin-Ciocâlteu reagent assay and the results are shown in Figure 3(a). The values varied from 33.2 to $95.8 \mathrm{mg}$ gallic acid/g of dry extract. Chloroform fraction contained the highest amount of phenolics (95.8 mg gallic acid/g), followed by butanol fraction ( $80.9 \mathrm{mg}$ gallic acid/g), whereas the lowest level was found in the hexane fraction $(33.2 \mathrm{mg}$ gallic acid/g). Total flavonoid content of $D$. viscosa extract and fractions was measured with standard aluminium chloride spectrophotometric method and the results are shown in Figure 3(b). The values varied from 22.6 to $41.5 \mathrm{mg}$ quercetin/g of dry extract. It was shown that chloroform fraction contained the highest total flavonoid content ( $41.5 \mathrm{mg} \mathrm{QU} / \mathrm{g}$ ), followed by butanol fraction (33.6 mg QU/g), whereas the lowest level was found in the hexane fraction $(22.6 \mathrm{mg} \mathrm{QU} / \mathrm{g})$.

4.3. D. Viscosa Induced Severe Toxicity and Teratogenicity in Zebrafish Embryos. The in vivo toxicity screening performed on zebrafish revealed that $D$. viscosa extracts were toxic towards the embryo's development and survival (Figure 4). The survival rate and effect on embryonic development were carried out first after overnight exposure and then every $24 \mathrm{~h}$

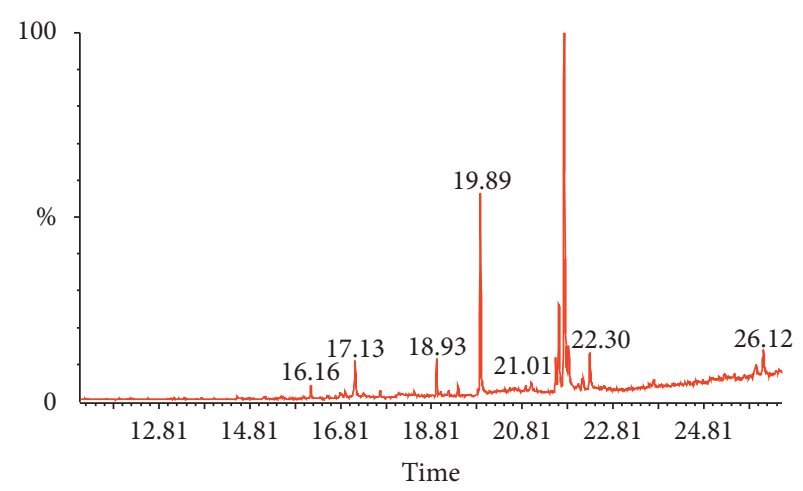

Figure 1: GC-MS analysis of DVHF.

by optical monitoring. The values obtained thus have proved the dose-dependent effects of $D$. viscosa extracts on embryos mortality and survival curves during the $96 \mathrm{~h}$. As shown in Figure 4 and Table 2, severe toxicity and teratogenic effects were observed in zebrafish embryos which were treated with either crude extracts or various fraction of $D$. viscosa. The D. viscosa extracts turned out to be very toxic to zebrafish embryos at concentration less than micrograms and kill the treated embryos within 12 hours of exposure. The hexane fraction was most toxic with $\mathrm{LD}_{50}$ values of $0.589 \pm 0.30 \mu \mathrm{g} /$ $\mathrm{mL}$ followed by crude extract with $\mathrm{LD}_{50}$ values $0.684 \pm 0.74$. The $\mathrm{LD}_{50}$ values for butanol and chloroform fractions were $3.139 \pm 0.57$ and $3.953 \pm 0.43 \mu \mathrm{g} / \mathrm{mL}$. The zebrafish embryos which were treated with sub-lethal concentration (less than $\mathrm{LD}_{50}$ values) exhibited severe embryonic abnormalities. Figure 5 shows the representative micrograph of control and treated embryos showing the teratogenic effect. As shown in Figure 5(a), the morphological features of mock treated embryos revealed a straight notochord, round yolk sac and pigmentation on the body and eyes, and normal heart shape and rate. The presence of pectoral fin in mock treated embryos at $72 \mathrm{~h}$ [27] verifies that the embryonic development in mock treated embryos is not hampered. The mock treated embryos also hatched normally $\leq 48 \mathrm{hpf}$. The zebrafish embryos treated with sub-lethal concentration $(0.5 \mu \mathrm{g} / \mathrm{mL})$ of crude extract of $D$. viscosa had bent spine, a large cardiac edema, and severe developmental delay as compared with mock treated counterpart (Figure 5(b)). The treated embryos did not hatch $\leq 48 \mathrm{hpf}$. The zebrafish embryos treated with sub-lethal concentration $(3.00 \mu \mathrm{g} / \mathrm{mL})$ of chloroform extract were mildly affected; however, the treated embryos had bent spine, large cardiac edema and cardiac looping (both chambers of the heart get connected with each other), and slow heart rate as compared to control embryos. The developmental stage criteria revealed a mild developmental delay in chloroform extract treated embryos; the presence of pectoral fin bud in these embryos showed that they are at $48 \mathrm{hpf}$ of developmental stage. The zebrafish embryos treated with hexane (Figure 5(e)) or butanol (Figure 5(d)) extract showed severe developmental abnormalities. The treated embryos had bent spine, absence of pigmentation, large yolk sac, and cardiac edema. The embryos were severely developmentally delayed as compared to their mock treated counterpart. The undeveloped heart was 
TABLe 1: GC-MS analysis of D. viscosa hexane fraction (DVHF).

\begin{tabular}{|c|c|c|c|c|}
\hline Compound name & Chemical formula & Molecular weight $(\mathrm{g} / \mathrm{mol})$ & Rt (min) & Area $\%$ \\
\hline (-)-Caryophyllene oxide & $\mathrm{C}_{15} \mathrm{H}_{24} \mathrm{O}$ & 220.35 & 16.16 & 1.280 \\
\hline 3,7,11,15-Tetramethyl-2-hexadecene & $\mathrm{C}_{20} \mathrm{H}_{40}$ & 280.5 & 18.92 & 2.590 \\
\hline Methyl ester of hexadecanoic acid & $\mathrm{C}_{17} \mathrm{H}_{34} \mathrm{O} 2$ & 270.5 & 19.89 & 26.330 \\
\hline 11,14,17-Eicosatrienoic acid & $\mathrm{C}_{20} \mathrm{H}_{34} \mathrm{O}_{2}$ & 306.5 & 21.62 & 5.170 \\
\hline 3,7,11,15-Tetramethyl-2-hexadecen-1-ol & $\mathrm{C}_{20} \mathrm{H}_{40} \mathrm{O}$ & 296.5 & 21.74 & 52.740 \\
\hline Alpha eudesmol & $\mathrm{C}_{15} \mathrm{H}_{26} \mathrm{O}$ & 222 & 17.13 & 4.520 \\
\hline Methyl ester of 9,12 octadecanoic acid & $\mathrm{C}_{19} \mathrm{H}_{34} \mathrm{O}_{2}$ & 294 & 21.55 & 1.630 \\
\hline 1,8 -Anhydro-Cis alpha-Copaene-8-ol & $\mathrm{C}_{15} \mathrm{H}_{22}$ & 202 & 22.30 & 2.800 \\
\hline$(1 \mathrm{~S}, 2 \mathrm{E}, 4 \mathrm{R}, 6 \mathrm{R}, 7 \mathrm{E}, 11 \mathrm{E}, 13 \mathrm{R})-2,7,11-$ Cembatriene-4,6,13 triol & $\mathrm{C}_{20} \mathrm{H}_{34} \mathrm{O}_{3}$ & 322 & 26.12 & 2.940 \\
\hline
\end{tabular}

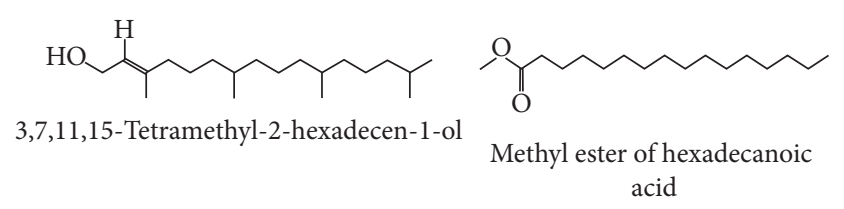

Figure 2: Major active constituents of DVHF.

observed in both of the extracts treated embryos. These embryos never hatched and also severe apoptosis was observed in these embryos as revealed by acridine orange staining (Figure 6).

\section{Discussion}

Any drug or herbal formula which is intended to be used in humans must first be tested in suitable experimental animals in order to evaluate its safety. D. viscosa is being used in many traditional herbal formulas. Even though there are not many toxicological studies, the available data suggests that $D$. viscosa did not induce toxicity in experimental animals. The ethanolic extract prepared from the leaves of $D$. viscosa inhibited the carrageenin induced paw inflammation and also did not cause any toxicity in mice [13]. In another study, no toxicological signs were noticed at a dose of $1250 \mathrm{mg} / \mathrm{kg}$ in rats [16]. In a dermotoxicity test, no irritation was noticed by $80 \%$ methanol extract of the leaves of $D$. viscosa in skin of mice and rats [29].

The embryos and infants are highly sensitive to chemicals that could cause serious damage to growth during development. The reproductive toxicity of various extracts of D. viscosa on embryonic development has never been investigated before this study. We used zebrafish embryos to find out the developmental toxicity of $D$. viscosa. Zebrafish embryos are being used successfully in many developmental toxicity testing screens. Using zebrafish in developmental toxicology has many advantages over other experimental animal model systems. Zebrafish embryos grow and hatch rapidly and have high fertility, and the small and transparent body is suitable for observation of internal organs with conventional microscopy. Large-scale screening in 96-well plate is possible for high-throughput chemical screens with zebrafish embryos. Moreover, easy exposure of embryos to chemicals with minimal amounts makes it an ideal model organism to test the developmental toxicity of chemical or extracts on a large scale [30-33]. The ex utero embryonic development taking place allows the observation of embryonic development without surgical intervention [34].

The most prominent toxic effect of D. viscosa on zebrafish embryos (with almost all the extracts) was egg coagulation or mortality within few hours of exposure. $100 \%$ of treated embryos died within 6 hours of exposure at concentration in microgram range. The most toxic extract was hexane fraction which induced $100 \%$ mortality in treated embryos $\leq 0.7 \mu \mathrm{g} / \mathrm{mL}$ followed by the crude extract where $100 \%$ mortality was observed with concentration $\leq 1.00 \mu \mathrm{g} / \mathrm{mL}$.

The phenol and flavonoid content of different extracts revealed that the hexane fraction of $D$. viscosa had the lowest phenol and flavonoid contents. The hexane fraction had phenol and flavonoid content of 33.2 and $22.6 \mathrm{mg} / \mathrm{mL}$, respectively, whereas the crude extract showed 47.9 and $27.9 \mathrm{mg} / \mathrm{mL}$ of phenol and flavonoid contents. The chloroform and butanol extract also exerted toxicity in treated zebrafish embryos, albeit at a higher concentration as compared to hexane and crude extract. The toxicity of the extracts of $D$. viscosa in zebrafish embryos has shown a direct relationship with the amount of phenol and flavonoid. The crude extract and hexane fraction induced the highest level of toxicity and contained the least amount of phenol and flavonoid as compared to other fractions. A similar kind of observation has been reported previously with other medicinal plants. The developmental toxicity of four different types of herbal plants (Andrographis paniculata, Cinnamon zeylanicum, Curcuma xanthorrhiza, Eugenia polyantha and Orthosiphon stamineus) was investigated in zebrafish embryos. It was shown that the extracts with low contents of phenol and flavonoid induced higher level of toxicity in zebrafish embryos [35].

It is well documented that there is direct relationship between phenolic and flavonoid contents and antioxidant activity of herbal extracts $[36,37]$. In one study, the antioxidant (free radical scavenging) activity in D. viscosa has been shown to be directly dependent on content of phenol flavonoid. The methanol extract of D. viscosa showed 50.72\% free radical scavenging activity at $50 \mu \mathrm{g} / \mathrm{mL}$ of phenol and it increased to $92.45 \%$ at $1000 \mu \mathrm{g} / \mathrm{mL}$ [12]. Similarly, another study reported $82 \%$ of radical scavenging inhibition activity with $300 \mu \mathrm{l}$ while $80 \%$ with $100 \mu \mathrm{l}$ of flower extract of D. viscosa [38].

The imbalance between the production of reactive oxygen species (ROS) and the antioxidant defenses caused 


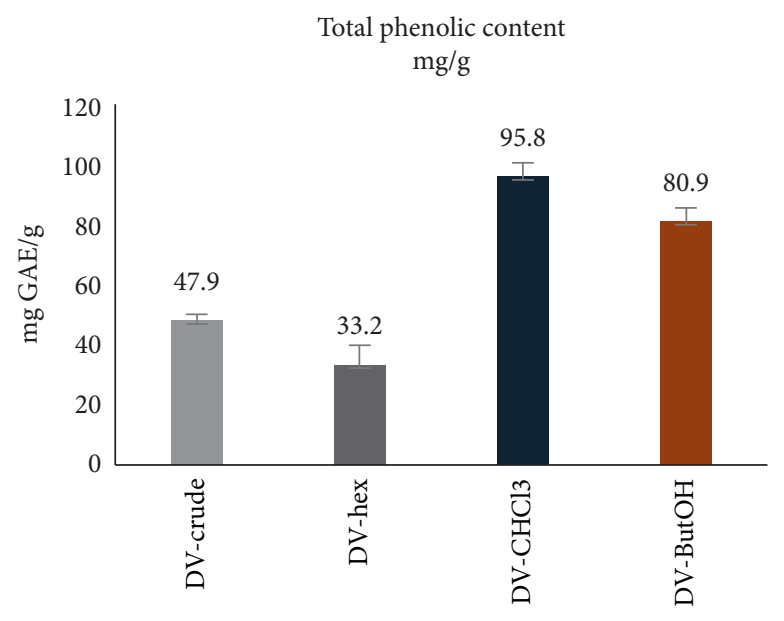

DV extract and fractions

(a)

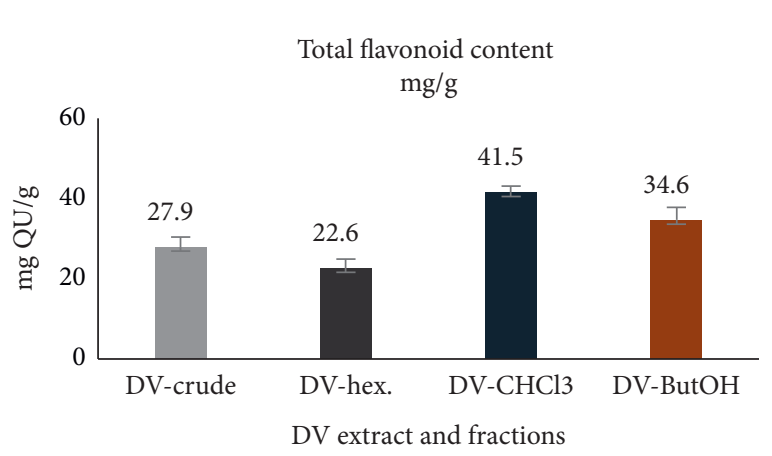

(b)

FIgURE 3: (a) Total phenolic content and (b) total flavonoid content of D. viscosa extract and fractions.

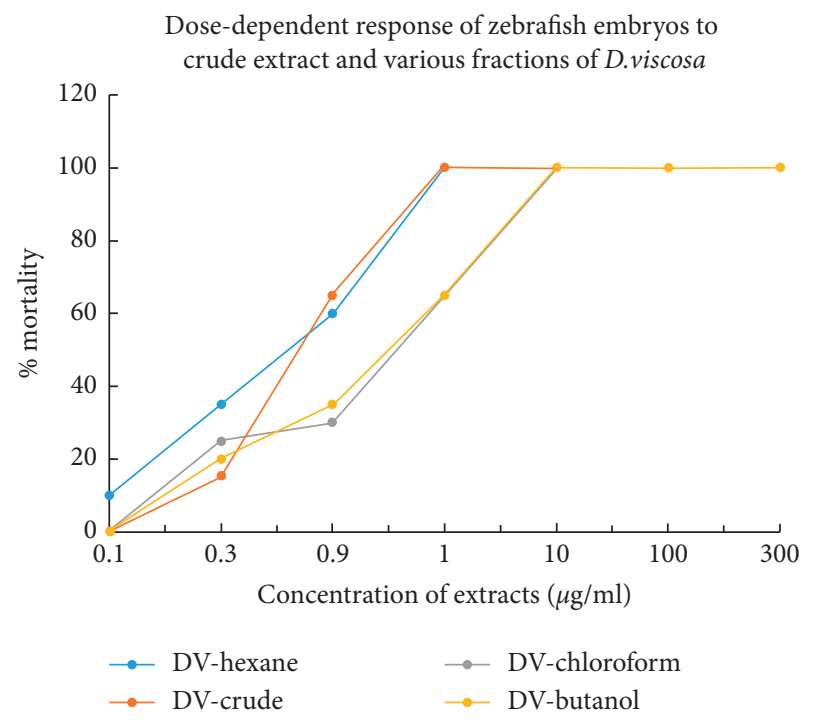

Figure 4: Dose-dependent response of zebrafish embryos on mortality exposed to crude extract and various fractions of D. viscosa.

TABLE 2: Response of zebrafish embryos in terms of mortality by exposure to crude leave extract and different fractions of $D$. viscosa.

\begin{tabular}{lc}
\hline Extract & $\mathrm{LD} 50 \mu \mathrm{g} / \mathrm{mL}$ \\
\hline DV-hex & $0.589 \pm 0.30$ \\
DV crude & $0.684 \pm 0.74$ \\
DV butanol & $3.139 \pm 0.57$ \\
DV chloroform & $3.953 \pm 0.43$ \\
\hline
\end{tabular}

pathogenesis of a variety of diseases. It is reported that, in newborns, inadequate antioxidant enzymes such as glutathione stores, and nutritional antioxidants elevate oxidative stress which would affect the development and growth of many organs [39]. It is quite likely that the embryonic abnormalities which have been observed in zebrafish embryos upon treatment of hexane fraction of $D$. viscosa leaves could be due to the elevated level of oxidative stress in these embryos.

The crude extract and various fractions of $D$. viscosa induced severe embryonic teratogenic effect in zebrafish embryos when treated with lower than $\mathrm{LD}_{50}$ concentration. Zebrafish embryos which were treated with crude extract or fractions exhibited severe developmental delay and did not hatch. The delayed hatching is supposed to be due to the absence of activity of zebrafish hatching enzyme 1 (ZHE1) which is secreted by hatching gland of zebrafish [40].

The methanolic extract of the leaves of $D$. viscosa has been shown to possess the antifertility activity in female rats. Reduction in the number of liters and early abortifacient and anti-implantation activity had also been observed in female rats which were treated with methanolic leaves extract of D. viscosa [41]. The infertility activity of D. viscosa extracts has not been investigated in adult zebrafish; however, the teratogenicity and delayed hatching of zebrafish embryos replicate the developmental toxicity phenotype which has been reported in rats.

The chemical composition analysis shows that 3,7,11,15tetramethyl-2-hexadecen-1-ol occupied 56\% and methyl ester of hexadecanoic acid $23 \%$ of hexane fraction of leaves of D. viscosa. 3,7,11,15-Tetramethyl-2-hexadecen-1-ol is phytol, an acyclic diterpene alcohol. Phytol induced toxicity, cytotoxicity, and genotoxicity in Allium cepa at concentrations of 2, 4, 8, and $16 \mathrm{mM}$ [42]. Phytol was reported to regulate the transcription factors PPAR-alpha and retinoid $X$ receptor (RXR) [43]. Phytol was identified as a major compound present in the leaf hexane fraction of Clinacanthus nutans and it exerted severe toxicity in zebrafish embryos at microgram concentration [44]. Phytol has been graded as category 1 toxic compound which can induce acute and chronic toxicity in aquatic organisms (https:// www.caymanchem.com/msdss/17401m.pdf), and the 


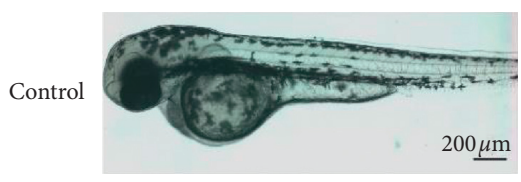

(a)

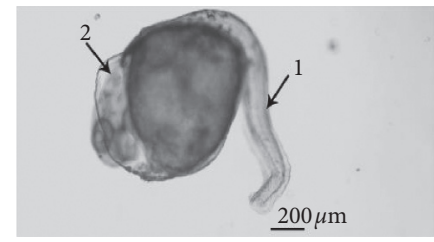

(d)

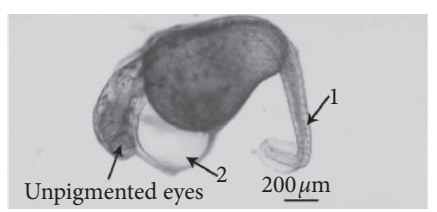

viscosa chloroform

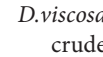

(b)

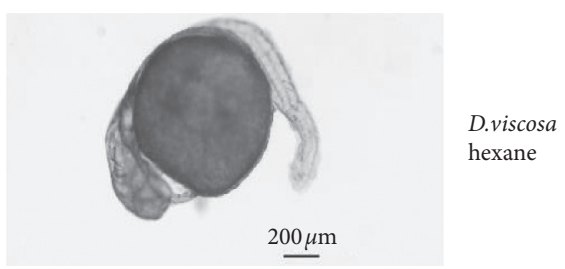

(e)

Figure 5: D. viscosa induced severe teratogenicity in zebrafish embryos. Representative micrograph of live zebrafish embryos mock treated (control) and treated with crude extract and various fractions of D. viscosa. The images were recorded after two days of exposure to zebrafish embryos to sub-lethal concentration of crude and various fractions. The images are arranged in order from mild to severe abnormalities, being the crude extract. The presence of pectoral fin mock treated embryos shows that the embryos are not developmentally delayed. The mock treated embryos have straight body with straight arrangement of notochord (black arrow, notochord in control) and pigments all around the body and also have pigment development in eyes, whereas the treated embryos lack the pigmentation and their body is curved due to abnormal development of notochord (represented by " 1 " in treated embryos). The treated embryos have large cardiac edema ( 2 in all the treated embryos). The pigment is also lacking in treated embryos except the embryos which were treated with crude extract.

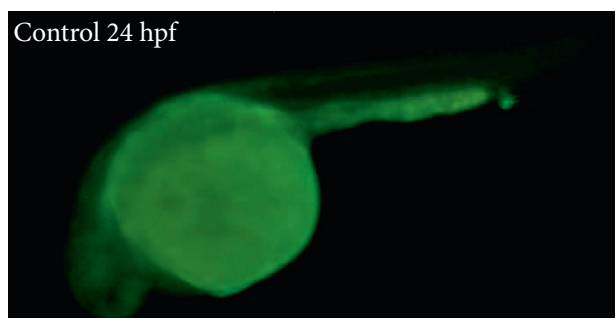

(a)

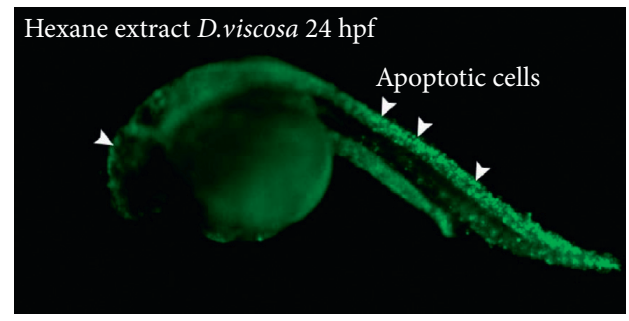

(b)

Figure 6: The hexane fraction of leaves extract of D. viscosa induced severe level of apoptosis in zebrafish embryos at 24 hpf. The level of apoptosis was evaluated in live zebrafish embryos which were treated with hexane fraction of $D$. viscosa. The hexane fraction induced severe embryonic toxicity; hence, the embryos treated with hexane fraction are shown. The live embryos are exposed to acridine orange as described in the methodology section. The images are taken by fluorescence microscope under FITC filter. Not many acridine orange positive (green) cells are observed in control (left image), whereas a lot of acridine positive cells are observed in zebrafish embryos which were treated with hexane fraction.

toxicity of D. viscosa which was observed in zebrafish embryos in this study could be due to the presence of phytol as a major compound in the hexane fraction.

The chemical structure of the phytol was searched by Swiss target protein prediction tool (http://old. swisstargetprediction.ch) to identify the possible protein target. As shown in Figure 7, the family of UDP-glucuronosyltransferase was identified as a protein target for phytol.

Family of UDP-glucuronosyltransferases (UGTs) catalyzes the glucuronidation reaction which is a major detoxification pathway in vertebrates. The impairment of UGT results in the accumulation of potentially toxic compounds [45]. Phytol could be one of the natural inhibitors of UGT. The phytol could have impaired the function of UGT in treated embryos which might have resulted in the accumulation of toxic compounds and affected the normal development.

\section{Conclusion}

Dodonaea viscosa is a very useful medicinal plant which is being used to treat various diseases in humans. The LD 50 values indicated that the solvent extracts of DV were very toxic in zebrafish embryos and killed developing embryos with concentrations in the microgram range. The 


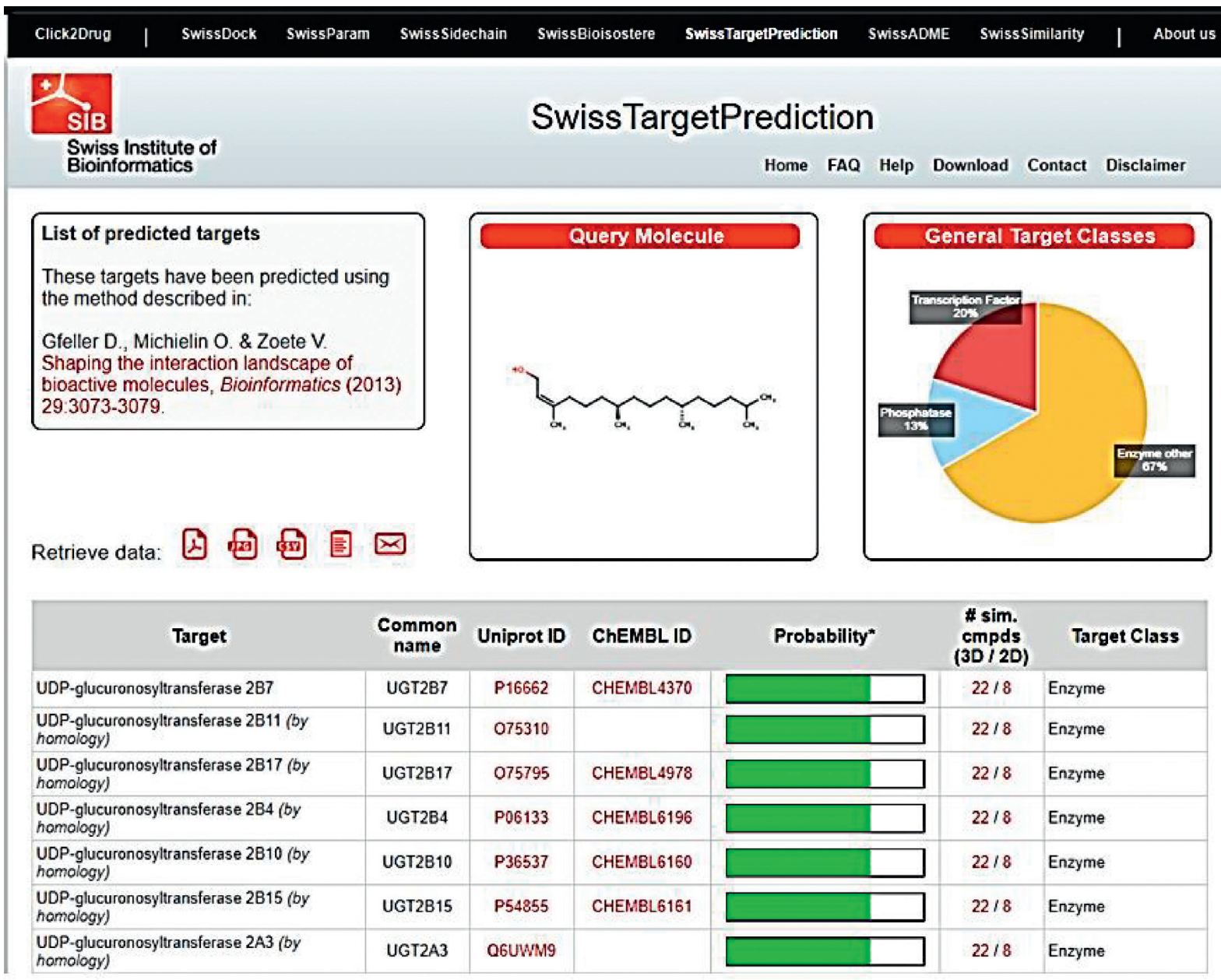

Figure 7: Swiss target protein prediction report of phytol.

morphological abnormalities which were recorded in zebrafish embryo were severe developmental delay, no pigmentation, and severe degenerated notochord which resulted in curved trunk. Moreover, severe cardiac edema and hypertrophy also resulted in treated embryos. The toxicity could be due to impaired UDP-glucuronosyltransferases enzyme due to the presence of major compound phytol (3,7,11,15-tetramethyl-2-hexadecen-1-ol). More detailed studies are needed to check the toxicity of D. viscosa in pregnant experimental animals. As D. viscosa has been reported to cause the infertility and abortion in female rats, its use and doses must be carefully monitored in pregnant patients.

\section{Data Availability}

All the available data are included within the manuscript.

\section{Conflicts of Interest}

The authors declare no conflicts of interest.

\section{Acknowledgments}

The authors extend their appreciation to the Deanship of Scientific Research at King Saud University for funding this work through research group no. RG-1441-486.

\section{References}

[1] M. S. Butler, "The role of natural product chemistry in drug discovery ${ }^{\dagger}, "$ Journal of Natural Products, vol. 67, no. 12, pp. 2141-2153, 2004.

[2] G. Di Fabio, V. Romanucci, M. Zarrelli, M. Giordano, and A. Zarrelli, "C-4 gem-dimethylated oleanes of Gymnema sylvestre and their pharmacological activities," Molecules, vol. 18, no. 12, pp. 14892-14919, 2013.

[3] V. Romanucci, D. D’Alonzo, A. Guaragna et al., "Bioactive compounds of Aristotelia chilensis stuntz and their pharmacological effects," Current Pharmaceutical Biotechnology, vol. 17, no. 6, pp. 513-523, 2016.

[4] S. E. Naranjo and H. M. Flint, "Spatial distribution of adult Bemisia tabaci (Homoptera: aleyrodidae) in cotton and development and validation of fixed-precision sampling plans for estimating population density," Environmental Entomology, vol. 24, no. 2, pp. 261-270, 1995. 
[5] A. Muhammad, I. Anis, A. Khan, B. P. Marasini, M. I. Choudhary, and M. R. Shah, "Biologically active C-alkylated flavonoids from Dodonaea viscosa," Archives of Pharmacal Research, vol. 35, no. 3, pp. 431-436, 2012.

[6] V. Rajeswari, S. Gajalakshmi, P. Jayanthi, and S. Vijayalakshmi, "Pharmacological activities of Dodonaea viscosa: a perspective review," Journal of Pharmacy Research, vol. 4, no. 10, pp. 3331-3333, 2011.

[7] V. Rajalakshimi, "CNS activity of ethyl acetate extract of stem bark of Dodonaea viscosa Linn," Indian Journal of Traditional Knowledge, vol. 18, no. 1, pp. 184-189, 2019.

[8] D. Lawal and I. Yunusa, "Dodonea Viscosa Linn: its medicinal, pharmacological and phytochemical properties," International Journal of Innovation and Applied Studies, vol. 2, no. 4, pp. 476-482, 2013.

[9] R. E. Shafek, N. H. Shafik, H. N. Michael, A. M. El-Hagrassi, and A. F. Osman, "Phytochemical studies and biological activity of Dodonaea viscosa flowers extract," Journal of Chemical and Pharmaceutical Research, vol. 7, no. 5, pp. 109-116, 2015.

[10] G. D. Mossa and A. A. Al-Shawi, "Induction of apoptosis through S-phase in human breast cancer MDA-MB231 cells by ethanolic extract of dodonaea viscose L.-an Iraqi medicine plant," Journal of Basrah Researches (Sciences), vol. 41, no. 1, 2015.

[11] S. Cao, P. Brodie, M. Callmander et al., "Antiproliferative triterpenoid saponins ofDodonaea viscosafrom the Madagascar dry forest(1)," Journal of Natural Products, vol. 72, no. 9, pp. 1705-1707, 2009.

[12] R. A. A. Mothana, S. A. A. Abdo, S. Hasson, F. M. N. Althawab, S. A. Z. Alaghbari, and U. Lindequist, "Antimicrobial, antioxidant and cytotoxic activities and phytochemical screening of some yemeni medicinal plants," Evidence-Based Complementary and Alternative Medicine, vol. 7, no. 3, pp. 323-330, 2010.

[13] N. M. Khalil, J. S. Sperotto, and M. P. Manfron, "Antiinflammatory activity and acute toxicity of Dodonaea viscosa," Fitoterapia, vol. 77, no. 6, pp. 478-480, 2006.

[14] B. Anilreddy, "Preparation, characterization and biological evaluation of some overview of Dodonaea viscosa Linn," J Pharm Sci Technol, vol. 1, no. 1, pp. 1-9, 2009.

[15] A. Pirzada, W. Shaikh, K. Usmanghani, and E. Mohiuddin, "Antifungal activity of Dodonaea viscosa Jacq extract on pathogenic fungi isolated from superficial skin infection," Pakistan Journal of Pharmaceutical Sciences, vol. 23, no. 3, pp. 337-340, 2010.

[16] M. Arun and V. V. Asha, "Gastroprotective effect of Dodonaea viscosa on various experimental ulcer models," Journal of Ethnopharmacology, vol. 118, no. 3, pp. 460-465, 2008.

[17] A. Barzinji, A. Nasher, R. Mothana, and M. Al-Hamadi, "In vitro antimalarial activity of selected Yemeni plants used in traditional medicine," International Journal of Medicinal Plants, vol. 107, pp. 526-535, 2014.

[18] A. Rojas, S. Cruz, V. Rauch, R. Bye, E. Linares, and R. Mata, "Spasmolytic potential of some plants used in Mexican traditional medicine for the treatment of gastrointestinal disorders," Phytomedicine, vol. 2, no. 1, pp. 51-55, 1995.

[19] T. Riaz, A. Abbasi, A. Aziz-Ur-Rehman, T. Shahzadi, M. Ajaib, and M. Khan, "Phytochemical screening, free radical scavenging, antioxidant activity and phenolic content of Dodonaea viscosa," Journal of the Serbian Chemical Society, vol. 77, no. 4, pp. 423-435, 2012.
[20] R. P. Adams, Identification of Essential Oil Components by Gas Chromatography/mass Spectrometry, Allured Publishing Corporation, Carol Stream, IL, USA, 2007.

[21] F. W. McLafferty and D. B. Stauffer, The Wiley/NBS Registry of Mass Spectral Data, Wiley, New York, NY, USA, 1989.

[22] K. Slinkard and V. L. Singleton, "Total phenol analysis: automation and comparison with manual methods," American Journal of Enology and Viticulture, vol. 28, no. 1, pp. 49-55, 1977.

[23] G. Sulaiman, N. Hussien, T. Marzoog, and H. Awad, "Phenolic content, antioxidant, antimicrobial and cytotoxic activities of ethanolic extract of Salix alba," American Journal of Biochemistry and Biotechnology, vol. 9, no. 1, pp. 41-46, 2013.

[24] M. Mervat, E. Far, A. Hanan, and A. Taie, "Antioxidant activities, total anthocyanins, phenolics and flavonoids contents of some sweet potato genotypes under stress of different concentrations of sucrose and sorbitol," Australian Journal of Basic and Applied Sciences, vol. 3, no. 4, pp. 3609-3616, 2009.

[25] U. Strähle, S. Scholz, R. Geisler et al., "Zebrafish embryos as an alternative to animal experiments-A commentary on the definition of the onset of protected life stages in animal welfare regulations," Reproductive Toxicology, vol. 33, no. 2, pp. $128-132,2012$.

[26] M. Westerfield, The Zebrafish Book. A Guide for the Laboratory Use of Zebrafish (Danio rerio), University of Oregon, 5274 University of Oregon, Eugene, OR, USA, 5th edition, 2007.

[27] C. B. Kimmel, W. W. Ballard, S. R. Kimmel, B. Ullmann, and T. F. Schilling, "Stages of embryonic development of the zebrafish," Developmental Dynamics, vol. 203, no. 3, pp. 253-310, 1995.

[28] W. J. Hayes and C. L. Kruger, Handbook of Hayes Principles and Methods of Toxicology, CRC Press, Boca Raton, NY, USA, 6th edition, 2014.

[29] K. Teshome, T. Gebre-Mariam, K. Asres, and E. Engidawork, "Toxicity studies on dermal application of plant extract of dodonaea viscosa used in ethiopian traditional medicine," Phytotherapy Research, vol. 24, no. 1, pp. 60-69, 2010.

[30] C. D. Jayasinghe and U. A. Jayawardena, "Toxicity assessment of herbal medicine using zebrafish embryos: a systematic review," Evidence-Based Complementary and Alternative Medicine, vol. 2019, Article ID 7272808, , 2019.

[31] X. Hong and J. Zha, "Fish behavior: a promising model for aquatic toxicology research," Science of the Total Environment, vol. 686, pp. 311-321, 2019.

[32] C. L. Souders, X. Liang, X. Wang, N. Ector, Y. H. Zhao, and C. J. Martyniuk, "High-throughput assessment of oxidative respiration in fish embryos: advancing adverse outcome pathways for mitochondrial dysfunction," Aquatic Toxicology, vol. 199, pp. 162-173, 2018.

[33] Z. Z. Zakaria, F. M. Benslimane, and G. K. Nasrallah, "Using zebrafish for investigating the molecular mechanisms of drug-induced cardiotoxicity," Biomed Research International, vol. 2018, Article ID 1642684, , 2018.

[34] S. Cassar, I. Adatto, J. L. Freeman et al., "Use of zebrafish in drug discovery toxicology," Chemical Research in Toxicology, vol. 33, no. 1, pp. 95-118, 2019.

[35] H. F. Ismail, Z. Hashim, W. T. Soon, N. S. A. Rahman, A. N. Zainudin, and F. A. A. Majid, "Comparative study of herbal plants on the phenolic and flavonoid content, antioxidant activities and toxicity on cells and zebrafish embryo," Journal of Traditional and Complementary Medicine, vol. 7, no. 4, pp. 452-465, 2017. 
[36] A. K. Esmaeili, R. M. Taha, S. Mohajer, and B. Banisalam, "Antioxidant activity and total phenolic and flavonoid content of various solvent extracts from in vivo and in vitro grown Trifolium pratense L. (Red Clover)," Biomed Research International, vol. 2015, Article ID 643285, , 2015.

[37] M. Sammar, B. Abu-Farich, I. Rayan, M. Falah, and A. Rayan, "Correlation between cytotoxicity in cancer cells and free radical-scavenging activity: in vitro evaluation of 57 medicinal and edible plant extracts," Oncology Letters, vol. 18, no. 6, pp. 6563-6571, 2019.

[38] N. H. S. Reham, S. Ezzat, M. Helana Naguib, M. Ali, H. El, and O. Abeer Fouad, "Phytochemical studies and biological activity of Dodonaea Viscosa flowers extract," Journal of Chemical and Pharmaceutical Research, vol. 7, no. 5, p. 8, 2015.

[39] R. L. Auten and J. M. Davis, "Oxygen toxicity and reactive oxygen species: the devil is in the details," Pediatric Research, vol. 66, no. 2, pp. 121-127, 2009.

[40] I. A. Muraina, W. Maret, N. R. Bury, and C. Hogstrand, "Hatching gland development and hatching in zebrafish embryos: a role for zinc and its transporters Zip10 and Znt1a," Biochemical and Biophysical Research Communications, vol. 528, no. 4, pp. 698-705, 2020.

[41] R. S. R. Ramya, C. Senthilkumar, J. Anudeepa, N. Santhi, and R. Venkata Narayanan, "Preliminary phytochemical and antifertility studies on Dodonea viscose Linn," Asian Journal of Research in Pharmaceutical Sciences, vol. 1, no. 3, p. 3, 2014.

[42] M. T. Islam, L. Streck, M. V. O. B. de Alencar et al., "Evaluation of toxic, cytotoxic and genotoxic effects of phytol and its nanoemulsion," Chemosphere, vol. 177, pp. 93-101, 2017.

[43] T. Goto, N. Takahashi, S. Kato et al., "Phytol directly activates peroxisome proliferator-activated receptor $\alpha(\operatorname{PPAR} \alpha)$ and regulates gene expression involved in lipid metabolism in PPAR $\alpha$-expressing HepG2 hepatocytes," Biochemical and Biophysical Research Communications, vol. 337, no. 2, pp. 440-445, 2005.

[44] S. Murugesu, A. Khatib, Q. U. Ahmed et al., “Toxicity study on Clinacanthus nutans leaf hexane fraction using Danio rerio embryos," Toxicology Reports, vol. 6, pp. 1148-1154, 2019.

[45] K. Grancharov, Z. Naydenova, S. Lozeva, and E. Golovinsky, "Natural and synthetic inhibitors of UDP-glucuronosyltransferase," Pharmacology \& Therapeutics, vol. 89, no. 2, pp. 171-186, 2001. 